\title{
Spatial sensitivity analysis of COVID-19 infections concerning the satellite-based four air pollutants levels
}

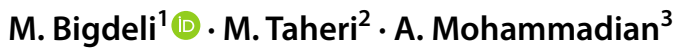

Received: 17 June 2020 / Revised: 5 October 2020 / Accepted: 21 December 2020 / Published online: 9 January 2021

(C) Islamic Azad University (IAU) 2021

\begin{abstract}
The novel coronavirus (COVID-19), first reported in late December 2019, has affected the lives of many people throughout the world. Significant studies have been conducted on this pandemic, some of which have addressed understanding the relationship between different air pollutants and confirmed cases. In this study, the effects of four air pollutants (carbon monoxide, nitrogen dioxide, ozone, and sulfur dioxide) were assessed from February 19 to March 22, 2020 to explore how they can affect COVID-19 contagion in Iran. The mean concentrations of air pollutants were extracted from Sentinel 5P data. The COVID-19 confirmed case densities of two provinces, Semnan and Qom, were more than all other provinces. The effect of pollutants on the confirmed case densities was analyzed using multiple linear regression in order to estimate the impact coefficients for individual provinces. The impact coefficients determine the level of each pollutant's contribution to the density of total confirmed cases. Carbon monoxide, nitrogen dioxide, sulfur dioxide, and ozone had both considerable negative and positive correlations with the density of confirmed COVID-19 cases, although sulfur dioxide was correlated more negatively than positively. In Semnan, a high hot spot province, nitrogen dioxide had the most significant effect on the density of confirmed cases among all pollutants, while the effect of carbon monoxide was greater in Qom. The results indicated that even short-term exposure to higher concentrations of the pollutants could lead to an increased risk of COVID-19 outbreaks, which should be considered in adopting adequate and appropriate control policies to manage the disease.
\end{abstract}

Keywords Air pollutants $\cdot$ Confirmed cases $\cdot$ Impact coefficient $\cdot$ Iran $\cdot$ Sentinel-5P

\section{Introduction}

The newly discovered coronavirus COVID-19 was first observed in Wuhan City, Hubei Province, China in late December 2019 (Ahmadi et al. 2020; Jahangiri et al. 2020; $\mathrm{Lu}$ et al. 2020; $\mathrm{Xu}$ et al. 2020; Yongjian et al. 2020). The coronavirus spread rapidly in just a few days out of China's boundaries and spread to almost all countries of the world

Editorial responsibility: Samareh Mirkia.

M. Bigdeli

mostafabigdeli@ut.ac.ir

1 Department of Environmental Engineering, School of Environment, College of Engineering, University of Tehran, Tehran, Iran

2 School of Civil Engineering, College of Engineering, University of Tehran, Tehran, Iran

3 Department of Civil Engineering, University of Ottawa, Ottawa, ON K1N6N5, Canada
(Chen et al. 2020; Jahangiri et al. 2020; Lu et al. 2020; Ogen 2020; Phan et al. 2020; WHO 2020b; Xu et al. 2020). Data from the World Health Organization (WHO) show that from February 19, 2020 to March 22, 2020, 257,182 new coronavirus cases were identified worldwide, and globally confirmed cases reached almost 333 thousand, with 14,509 deaths (WHO 2020a, c). In the same period, throughout Iran's provinces, 21,638 COVID-19 cases have been confirmed, including 1682 deaths (https://www.behdasht.gov. ir). Symptoms of fever, dry cough, and sore throat have been observed in many infected patients (Huang et al. 2020; Jiang et al. 2020; Ogen 2020; Sohrabi et al. 2020; Yongjian et al. 2020), and in some cases, a severe acute respiratory syndrome was observed which led to death (Chen et al. 2020; Guo et al. 2020; Mehta et al. 2020; Rodriguez-Morales et al. 2020; Sohrabi et al. 2020). Therefore, to determine the role of the most significant factors affecting COVID-19 contagion in urban areas, especially in megacities, multiple studies have been conducted (Bontempi 2020; Chan et al. 2020; Domingo and Rovira 2020; Li et al. 2020; Rastogi et al. 
2020; Wang et al. 2020a). Many factors, including climatic parameters such as temperature and relative humidity (Zhu and Xie 2020), population density (Kraemer et al. 2020), and quality of medical care (Wang et al. 2020b) affect the virus's transmission. To pursue the matter further, the impact of short-term exposure to air pollutants should be particularly considered (Bashir et al. 2020).

Many studies have shown that ambient air pollutants have adverse effects on the human respiratory system, and have reported that chronic respiratory illnesses can also be caused by long-term exposure to major air pollutants (Becker and Soukup 1999; Cai et al. 2007; Chauhan and Johnston 2003; Chen et al. 2007; Ciencewicki and Jaspers 2007; Horne et al. 2018; Mehta et al. 2013; Phosri et al. 2019; Xie et al. 2019; $\mathrm{Xu}$ et al. 2016). Carbon monoxide (CO), nitrogen dioxide $\left(\mathrm{NO}_{2}\right)$, ozone $\left(\mathrm{O}_{3}\right)$, and sulfur dioxide $\left(\mathrm{SO}_{2}\right)$ are significant harmful ambient air pollutants in many urban regions. The risk of adverse cardiopulmonary events, including death, can be increased by continuous exposure to $\mathrm{CO}$ (Chen et al. 2007). High concentrations of $\mathrm{NO}_{2}$, as a highly reactive gas produced during combustion, cause catastrophic injury to the human lung (Beelen et al. 2008; Chen et al. 2007; Hoek et al. 2013). $\mathrm{NO}_{2}$ also contributes to the formation of some harmful secondary air pollutants such as $\mathrm{O}_{3}$ (Khoder 2002). Tropospheric $\mathrm{O}_{3}$ levels harm public health in areas throughout the world. Many studies have shown that respiratory irritation and decreased lung function from damaged lung tissue, causing pulmonary and heart disease, are caused by short-term exposure to high levels of $\mathrm{O}_{3}$ (Bell et al. 2004; Filippidou and Koukouliata 2011; Gryparis et al. 2004; Parodi et al. 2005). $\mathrm{SO}_{2}$ can also lead to respiratory problems, especially in patients with pulmonary underlying disease (Smith et al. 1977).

COVID-19 can disperse in aerosol form and remain viable for hours in ambient air (Van Doremalen et al. 2020). Hence, a tangible understanding of the impact of ambient air pollutants on the novel coronavirus infection seems necessary. This study aims to assess the relationship between the satellite-based concentrations of four air pollutants and COVID-19 cases in 31 provinces in Iran by combining two databases: the tropospheric concentration of four air pollutants (i.e., $\mathrm{CO}, \mathrm{NO}_{2}, \mathrm{O}_{3}$, and $\mathrm{SO}_{2}$ ) and the number of confirmed cases between February 19 to March 22, 2020. As well, the impact coefficients of each pollutant are introduced separately for Iran's provinces, and the most vulnerable provinces are determined. Finally, discussion and concluding remarks are provided.

\section{Materials and methods}

\section{Study area}

The Islamic Republic of Iran, with over 80 million inhabitants and an area of $1648,195 \mathrm{~km}^{2}$, is located in western Asia in a transcontinental region, i.e., the Middle East. Iran lies within latitudes $24^{\circ}$ and $40^{\circ} \mathrm{N}$ and longitudes $44^{\circ}$ and $64^{\circ} \mathrm{E}$. It consists of 31 provinces with a wide range of population densities (Fig. 1). The climate in Iran is classed as between arid and semiarid. Topography, meteorological conditions, and emissions from mobile and stationary sources
Fig. 1 Population densities (ratios of population size to area) in Iran's provinces

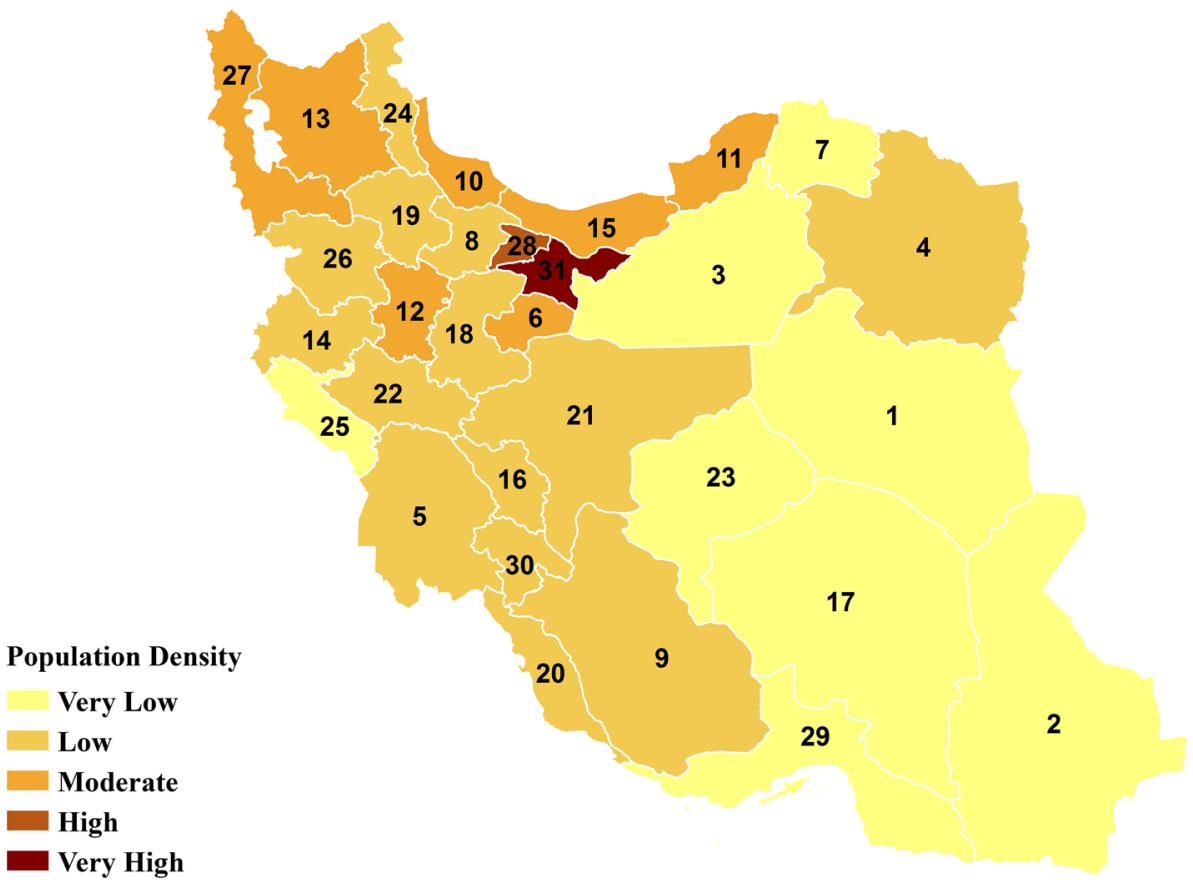


in many megacities in Iran contribute to poor air quality on many days of the year.

\section{Data collection}

The daily numbers of coronavirus cases for each province were collected from the official website of the Ministry of Health and Medical Education (https://www.behdasht.gov. ir). The provincial population sizes were obtained from the Statistical Center of Iran (SCI) (https://www.amar.org.ir). It should be noted that the number of cases in each province is only reported from February 19, as the starting point of the outbreak in Iran, to March 22, 2020, as shown in Table 1. The maximum numbers of confirmed cases are in Tehran, Isfahan, and Mazandaran provinces, while the minimum numbers of confirmed cases belong to Bushehr,
Chaharmahal and Bakhtiari, and Kohgiluyeh and BoyerAhmad provinces.

Satellite-based data can be used for monitoring air quality and performing health research (Omrani et al. 2020; Putrenko and Pashynska 2017). To obtain the daily tropospheric concentrations of $\mathrm{CO}, \mathrm{NO}_{2}, \mathrm{O}_{3}$, and $\mathrm{SO}_{2}$ from the surface up to $\sim 10 \mathrm{~km}$, satellite data were extracted from the Sentinel-5P Pre-Operations Data Hub (https://s5phu b.copernicus.eu/). The Sentinel-5P, a satellite with a spectral resolution of $0.25-0.55 \mathrm{~nm}$ and global daily coverage of $7 \times 7 \mathrm{~km}^{2}$, is an Earth-observation satellite. It was developed and launched in October 2017 by the European Commission under the "Copernicus" Program. The satellite carries a TROPOspheric Monitoring Instrument (TROPOMI) that provides a $3.5 \times 7 \mathrm{~km}^{2}$ spatial resolution of the measurements for all trace gases, except for $\mathrm{CO}$, which has a

Table 1 Statistical data from February 19 to March 22, 2020

\begin{tabular}{|c|c|c|c|c|c|c|c|}
\hline \multirow[t]{2}{*}{ No. } & \multirow[t]{2}{*}{ Province } & \multirow{2}{*}{$\begin{array}{l}\text { Total confirmed } \\
\text { COVID-19 cases }\end{array}$} & \multirow[t]{2}{*}{ Population } & \multicolumn{4}{|c|}{ Average concentration } \\
\hline & & & & $\mathrm{CO}\left(\mathrm{mmol} / \mathrm{m}^{2}\right)$ & $\mathrm{NO}_{2}\left(\mu \mathrm{mol} / \mathrm{m}^{2}\right)$ & $\mathrm{O}_{3}\left(\mathrm{mmol} / \mathrm{m}^{2}\right)$ & $\mathrm{SO}_{2}\left(\mathrm{mmol} / \mathrm{m}^{2}\right)$ \\
\hline 1 & South Khorasan & 178 & 768,898 & 0.58 & 11.66 & 0.71 & 0.40 \\
\hline 2 & Sistan and Balouchestan & 134 & $2,775,014$ & 1.02 & 13.16 & 0.59 & 0.57 \\
\hline 3 & Semnan & 645 & 702,360 & 0.88 & 12.58 & 0.65 & 0.53 \\
\hline 4 & Razavi Khorasan & 858 & $6,434,501$ & 1.12 & 12.92 & 0.64 & 0.66 \\
\hline 5 & Khuzestan & 444 & $4,710,509$ & 0.79 & 12.39 & 0.67 & 0.48 \\
\hline 6 & Qom & 1178 & $1,292,283$ & 0.96 & 13.12 & 0.61 & 0.62 \\
\hline 7 & North Khorasan & 165 & 863,092 & 0.98 & 12.78 & 0.63 & 0.65 \\
\hline 8 & Qazvin & 669 & $1,273,761$ & 0.65 & 11.78 & 0.72 & 0.44 \\
\hline 9 & Fars & 505 & $4,851,274$ & 1.09 & 13.02 & 0.61 & 0.61 \\
\hline 10 & Gilan & 1191 & $2,530,696$ & 0.79 & 12.16 & 0.66 & 0.48 \\
\hline 11 & Golestan & 391 & $1,868,619$ & 1.05 & 13.42 & 0.64 & 0.63 \\
\hline 12 & Hamedan & 175 & $1,758,268$ & 0.96 & 13.75 & 0.62 & 0.63 \\
\hline 13 & East Azerbaijan & 813 & $3,909,652$ & 1.11 & 12.62 & 0.61 & 0.57 \\
\hline 14 & Kermanshah & 243 & $1,952,434$ & 1.02 & 12.91 & 0.61 & 0.52 \\
\hline 15 & Mazandaran & 1700 & $3,283,582$ & 0.84 & 12.82 & 0.67 & 0.55 \\
\hline 16 & Chaharmahal and Bakhtiari & 68 & 947,763 & 1.07 & 12.81 & 0.60 & 0.61 \\
\hline 17 & Kerman & 169 & $3,164,718$ & 1.09 & 13.64 & 0.61 & 0.57 \\
\hline 18 & Markazi & 882 & $1,429,475$ & 1.10 & 13.60 & 0.62 & 0.64 \\
\hline 19 & Zanjan & 394 & $1,057,461$ & 1.02 & 13.42 & 0.61 & 0.60 \\
\hline 20 & Bushehr & 55 & $1,163,400$ & 0.67 & 11.66 & 0.68 & 0.48 \\
\hline 21 & Isfahan & 1979 & $5,120,850$ & 0.94 & 12.52 & 0.64 & 0.52 \\
\hline 22 & Lorestan & 476 & $1,760,649$ & 0.92 & 13.08 & 0.62 & 0.60 \\
\hline 23 & Yazd & 725 & $1,138,533$ & 0.89 & 12.37 & 0.63 & 0.53 \\
\hline 24 & Ardabil & 289 & $1,270,420$ & 1.09 & 13.35 & 0.61 & 0.57 \\
\hline 25 & Ilam & 183 & 580,158 & 1.07 & 12.84 & 0.63 & 0.62 \\
\hline 26 & Kordestan & 238 & $1,603,011$ & 0.70 & 11.90 & 0.69 & 0.49 \\
\hline 27 & West Azerbaijan & 395 & $3,265,219$ & 0.94 & 12.84 & 0.60 & 0.61 \\
\hline 28 & Alborz & 1177 & $2,712,400$ & 1.11 & 12.39 & 0.62 & 0.58 \\
\hline 29 & Hormozgan & 148 & $1,776,415$ & 0.79 & 12.34 & 0.66 & 0.47 \\
\hline 30 & Kohgiluyeh and Boyer-Ahmad & 73 & 713,052 & 0.70 & 11.57 & 0.67 & 0.48 \\
\hline 31 & Tehran & 5098 & $13,267,637$ & 0.73 & 11.97 & 0.67 & 0.47 \\
\hline
\end{tabular}


$7 \times 7 \mathrm{~km}^{2}$ spatial resolution. In this study, Level 2 geophysical products were collected using "wget," which is a computer program that retrieves content from web servers (https ://scihub.copernicus.eu/userguide/BatchScripting).

Daily air pollutant data in a netCDF format were used for both spatial and temporal observations. Since TROPOMI measurements have a varied spatial distribution of grid cells and depend on the viewing zenith angle in every orbit at the moment of observation, each product was resampled for the study area on the regular grid with the same spatial resolution. The dataset was re-projected by latitude/longitude WGS84 using R statistical software (version 3.6.3) (Omrani et al. 2020). Some factors such as cloud cover, saturation, and geometry affect the data quality of individual observations. Therefore, to rectify errors and incomplete retrievals, the data were cleaned using a quality assurance value marked by a 'qa_value' which ranges between 0 (no data) and 1 (full data). Measurements with a 'qa_value' above 0.5 provided by TROPOMI were used, and outliers were eliminated based on Copernicus specifications (Copernicus 2019). For further analysis, spatial assessment of the air pollutant density was done by separately using the monthly raw data for the mean concentrations of each pollutant for all provinces, which was processed by a Python code. Table 1 shows the statistics for the satellite-based mean concentrations of the four air pollutants in each province during the observation period. The mean concentration values for $\mathrm{CO}$, $\mathrm{NO}_{2}, \mathrm{O}_{3}$, and $\mathrm{SO}_{2}$ varied between 0.58 and $1.12 \mathrm{mmol} / \mathrm{m}^{2}$, 11.57 and $13.75 \mu \mathrm{mol} / \mathrm{m}^{2}, 0.59$ and $0.72 \mathrm{mmol} / \mathrm{m}^{2}$, and 0.40 and $0.66 \mathrm{mmol} / \mathrm{m}^{2}$, respectively.

\section{Multiple linear regression}

In this study multiple linear regression (MLR) (İçağa and Sabah 2009; Ng and Awang 2018; Sousa et al. 2007; UlSaufie et al. 2012) was used to determine the relationship between daily COVID-19 confirmed cases density (CCD) and the average concentrations of the four criteria air pollutants (i.e., $\mathrm{CO}, \mathrm{NO}_{2}, \mathrm{O}_{3}$, and $\mathrm{SO}_{2}$ ). $\mathrm{CCD}$ is obtained by dividing the number of total confirmed cases by the population size. The basic model using the least square method was defined as follows:

$N_{\mathrm{CCD}}=a \mathrm{C}_{\mathrm{CO}}+b \mathrm{C}_{\mathrm{NO}_{2}}+c \mathrm{C}_{\mathrm{O}_{3}}+d \mathrm{C}_{\mathrm{SO}_{2}}$

where $N_{\mathrm{CCD}}$ indicates the normalized CCD, $, b, c$, and $d$ are the impact coefficients of $\mathrm{CO}, \mathrm{NO}_{2}, \mathrm{O}_{3}$, and $\mathrm{SO}_{2}$, respectively. $C_{\mathrm{CO}}, C_{\mathrm{NO} 2}, C_{\mathrm{O} 3}$, and $C_{\mathrm{SO} 2}$ indicate the daily normalized average concentrations of $\mathrm{CO}, \mathrm{NO}_{2}, \mathrm{O}_{3}$, and $\mathrm{SO}_{2}$, respectively. The normalized values were obtained by dividing the difference between the daily and the average values by the standard deviations of their daily values.
The above four air pollutants collectively covered 83,624 grid cells over Iran. The impact coefficients determine the contribution level of each pollutant to the occurrence of COVID-19 infections. These coefficients vary between -1 and 1 to, respectively, indicate relative decreasing and increasing effects.

\section{Results and discussion}

\section{Results}

\section{Descriptive analysis}

The spatial distribution of CCD is shown in Fig. 2. Mapping the CCD over Iran revealed major COVID-19 'hotspots' in Semnan and Qom (which include nearly 9\% of all confirmed cases). Aside from these two provinces, nine other provinces located close to the center of Iran had high CCDs and collectively included $64 \%$ of all cases. In contrast, five southern provinces, particularly Bushehr and Sistan and Balouchestan, had the lowest CCDs due to their lower case numbers and populations.

The provincial mean concentrations of $\mathrm{CO}, \mathrm{NO}_{2}, \mathrm{O}_{3}$, and $\mathrm{SO}_{2}$ and the corresponding CCDs are shown in Fig. 3. The mean $\mathrm{CO}$ concentrations in 13 provinces which collectively included more than $63 \%$ of all cases were over $1 \mathrm{mmol} / \mathrm{m}^{2}$. The mean $\mathrm{NO}_{2}$ concentrations were higher than $13 \mu \mathrm{mol} /$ $\mathrm{m}^{2}$ for 10 provinces which collectively included $58 \%$ of all cases. The average $\mathrm{O}_{3}$ concentrations in 11 provinces which collectively included $20 \%$ of total cases were more than $0.65 \mathrm{mmol} / \mathrm{m}^{2}$, and 12 provinces with average $\mathrm{SO}_{2}$ concentrations over $0.6 \mathrm{mmol} / \mathrm{m}^{2}$ encompassed $55 \%$ of confirmed cases. It should be noted that Semnan and Qom had both high CCDs and high concentrations of the four pollutants. Moreover, three provinces which collectively included $4 \%$ of total confirmed cases had mean $\mathrm{CO}$ concentrations lower than $0.7 \mathrm{mmol} / \mathrm{m}^{2}$. Six provinces had average $\mathrm{NO}_{2}$ concentrations lower than $12 \mu \mathrm{mol} / \mathrm{m}^{2}$ and collectively included $5 \%$ of all confirmed cases. The mean $\mathrm{O}_{3}$ concentrations were less than $0.6 \mathrm{mmol} / \mathrm{m}^{2}$ for two provinces that together encompassed only $3 \%$ of all confirmed cases. There were also two provinces with average $\mathrm{SO}_{2}$ concentrations lower than $0.45 \mathrm{mmol} / \mathrm{m}^{2}$ that included only one percent of total confirmed cases.

\section{Air pollutant impact coefficients}

The spatial distribution of the four impact coefficients $a, b$, $c$, and $d$, corresponding to $\mathrm{CO}, \mathrm{NO}_{2}, \mathrm{O}_{3}$, and $\mathrm{SO}_{2}$, respectively, are shown in Fig. 4. The results show that the impact 
Fig. 2 Confirmed COVID-19 Case Densities (CCD) from February 19 to March 22, 2020

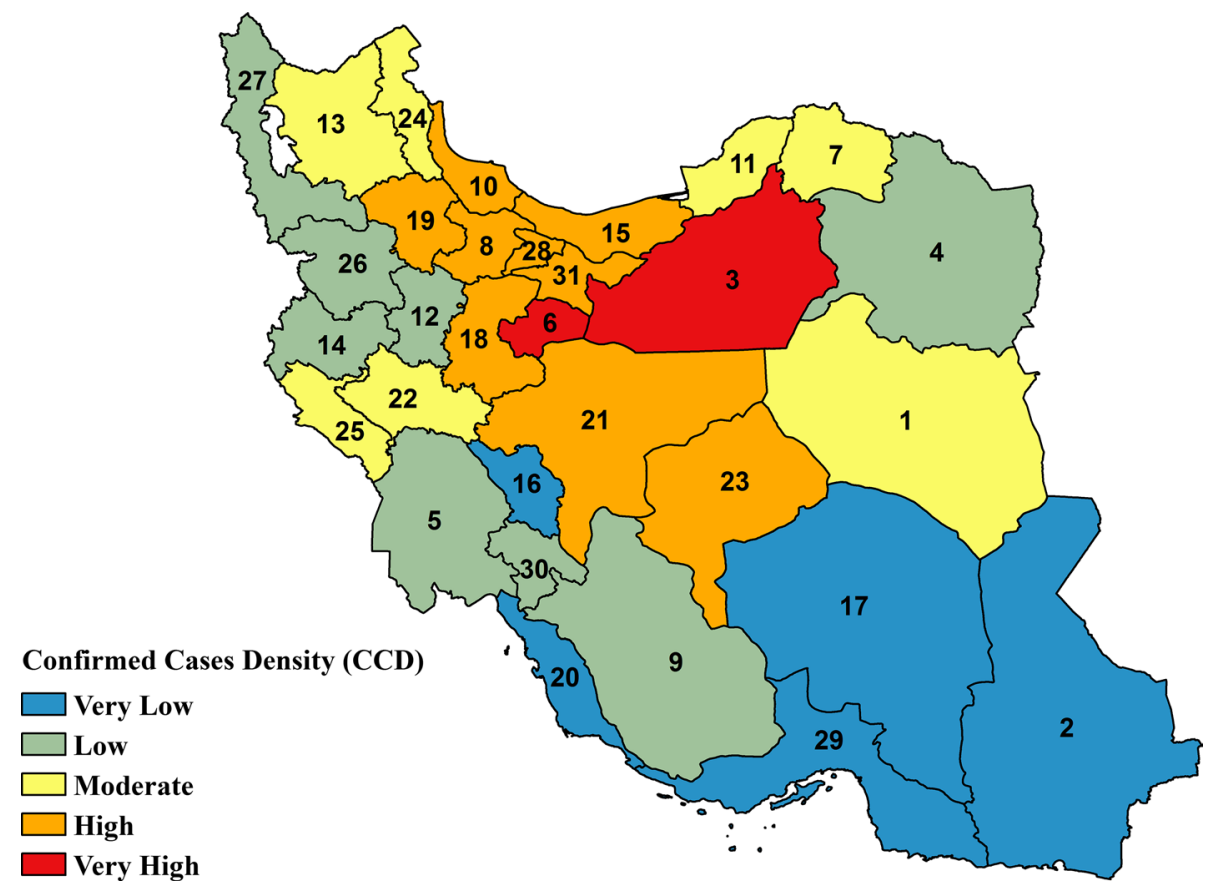

coefficients $a, b, c$, and $d$ varied between -0.4 and $0.6,-0.3$ and $0.8,-0.5$ and 0.6 , and -0.6 and 0.8 , respectively. There were five provinces with $a$ coefficients higher than 0.4 , with Tehran having the largest value, and nine provinces with $a$ coefficients smaller than -0.2 , with South Khorasan having the lowest. The impact coefficient $b$ was larger than 0.4 for seven provinces and smaller than 0 for nine provinces, with Golestan having the highest and North Khorasan having the lowest. The impact coefficient $c$ was over 0.4 for four provinces and less than -0.25 for five provinces, of which Kohgiluyeh and Boyer-Ahmad had the highest and Markazi the lowest. The impact coefficient $d$ was larger than 0.4 for four provinces, of which Chaharmahal and Bakhtiari had the highest, and smaller than -0.2 for four provinces, of which Golestan had the lowest. Also, the provinces with the highest $a, b, c$, and $d$ coefficients had over $31 \%, 13 \%, 3 \%$, and $3 \%$ of all confirmed cases, respectively. Conversely, the provinces with the lowest $a, b, c$, and $d$ coefficients had over $22 \%, 37 \%$, $33 \%$, and $9 \%$ of total confirmed cases, respectively.

\section{Sensitivity analysis}

In order to perform a provincial sensitivity analysis and to figure out the different effects of the impact coefficients on each province, the influences of each impact coefficient on the density of confirmed COVID-19 cases along with the CCDs are shown in Fig. 5. Each province had different impact coefficients during the study period. Accordingly, the absolute (regardless of positive or negative sign) value of the impact coefficient $a$ was higher than other coefficients in 10 provinces which included $51 \%$ of all confirmed cases. The absolute values of the impact coefficient $b$ outnumbered the other three coefficients in 10 provinces which collectively included $32 \%$ of total confirmed cases, while the impact coefficient $c$ had the highest absolute value among the other coefficients in eight provinces that collectively encompassed $15 \%$ of all confirmed cases. Among the four impact coefficients, the absolute value of coefficient $d$ was highest in merely three provinces that collectively included $2 \%$ of confirmed cases. However, in comparison with the other coefficients, the absolute value of impact coefficient $a$ was lowest in only five provinces that collectively had $11 \%$ of all cases. The absolute value of impact coefficient $b$ was lower than all other coefficients in seven provinces which collectively had $14 \%$ of total cases. The impact coefficient $c$ had the lowest value compared with the other coefficients in 12 provinces which collectively had $41 \%$ of all confirmed cases. The absolute value of coefficient $d$ was lowest in seven provinces which collectively had $34 \%$ of total confirmed cases compared with the other impact coefficients. Therefore, the overall trend of the four impact coefficients was such that the absolute values of the coefficients $a, b$ and $d$, and $c$ were significant in many provinces, respectively. It should be noted that the impact coefficients had negative or positive associations in various provinces. Positive values imply relative increasing effect, while negative values indicate a relative decreasing impact on the density of COVID-19 confirmed cases. Among all provinces, the impact coefficients $a, b, c$, and $d$ had a positive correlation in 16,22,17, and 13 provinces, respectively.

The value of impact coefficient $a$ outnumbered the other coefficients' values, regardless of positive or negative 

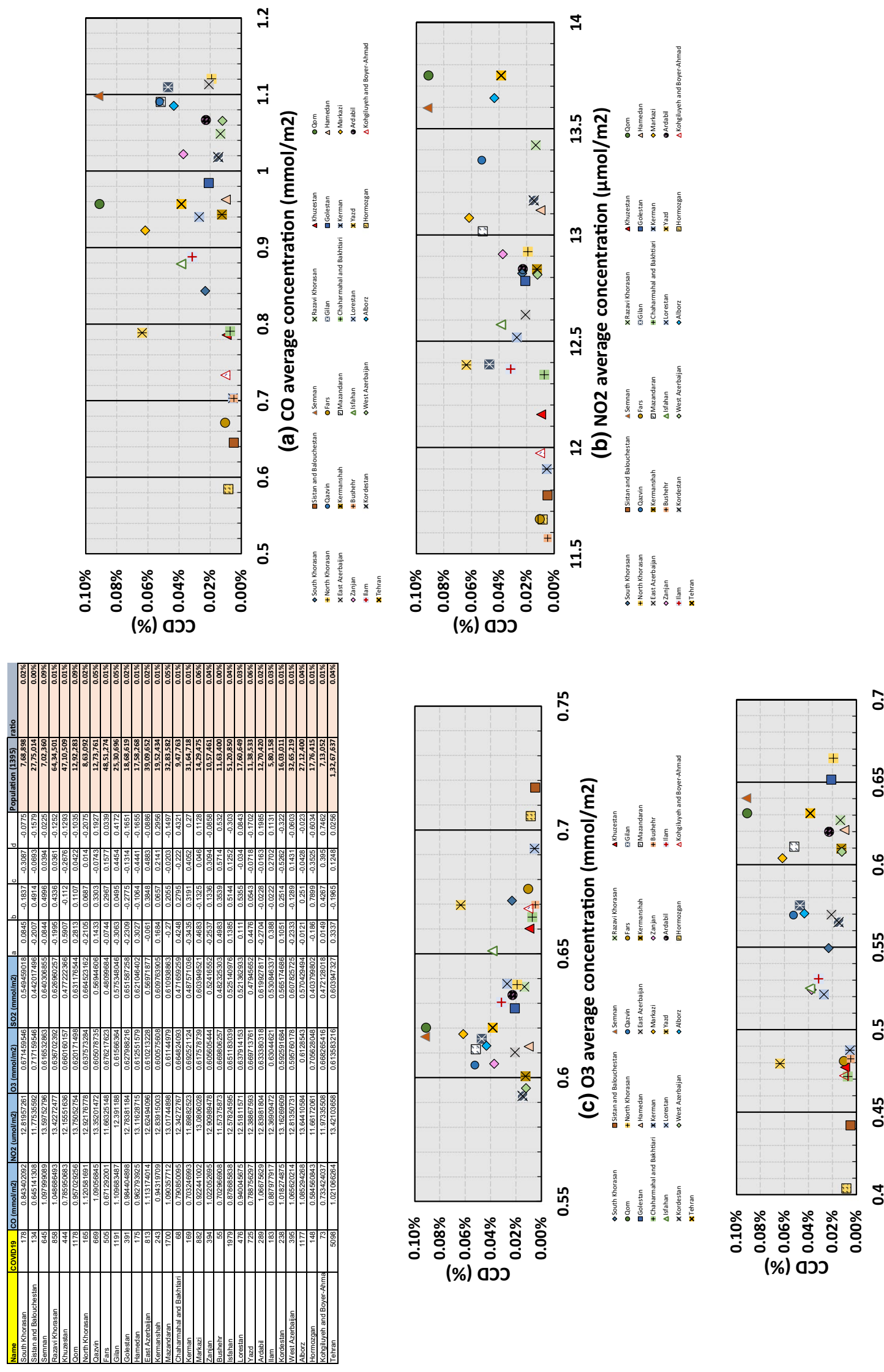

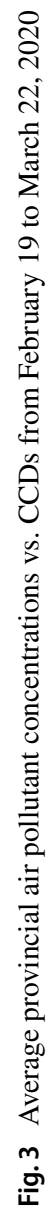



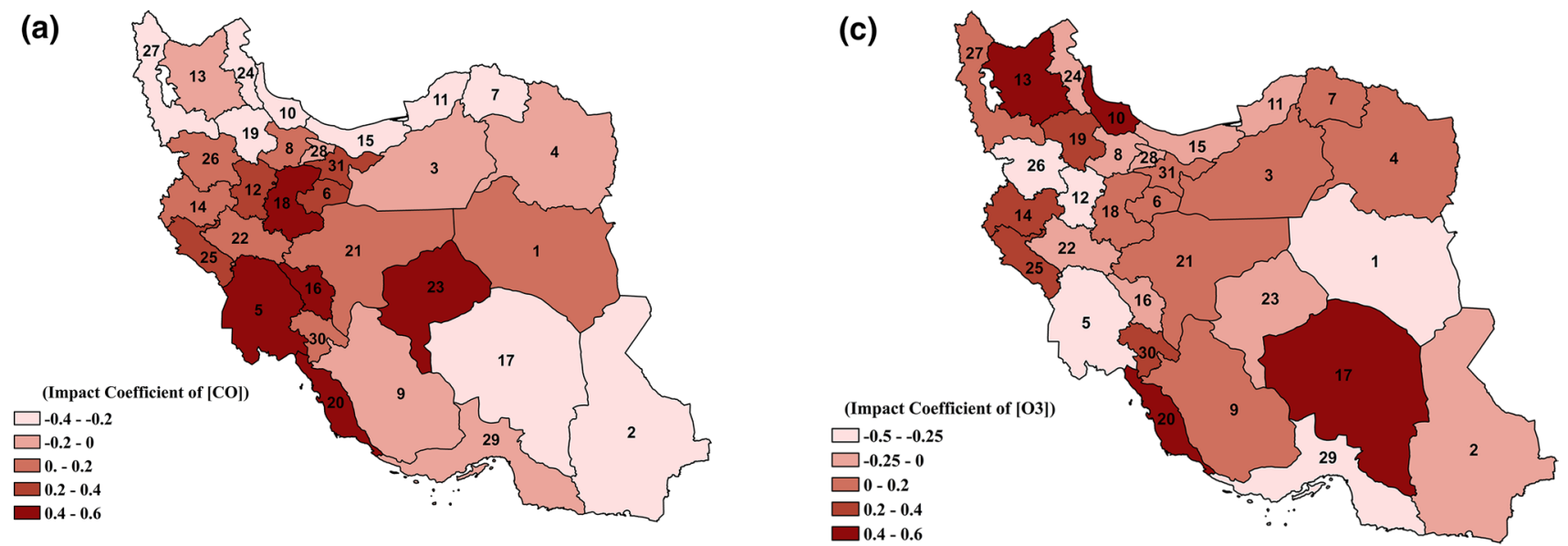

(b)

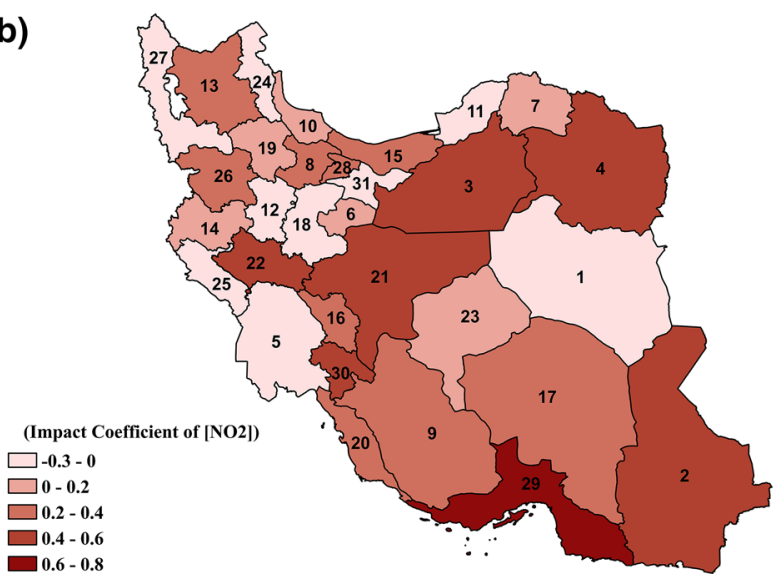

(d)

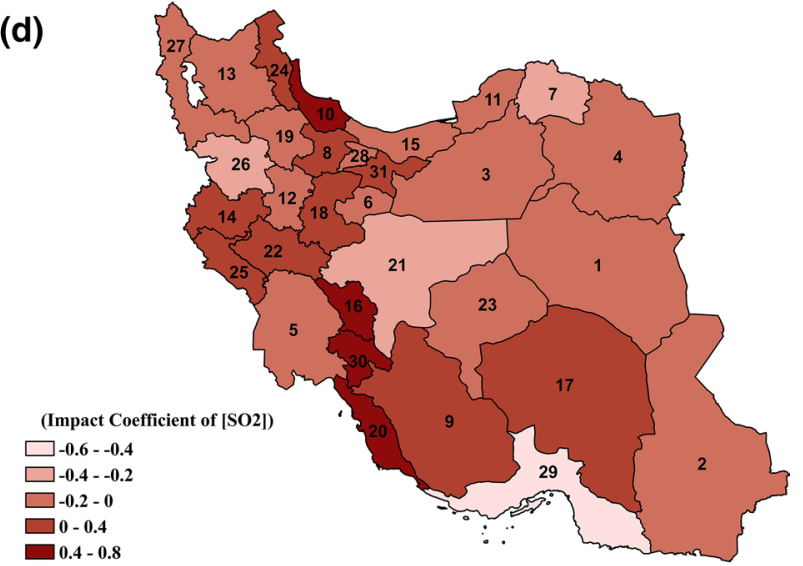

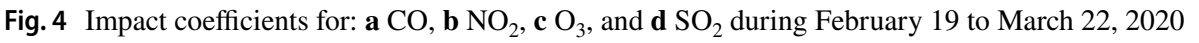

influences, in Qom, Yazd, and Markazi as the three regions with high CCDs. Exceptionally, in Semnan, which had the highest CCD, the value of impact coefficient $b$ was larger than that of $a$.

\section{Discussion}

The results of the investigation into the COVID-19 outbreak in Iran's provinces show that provinces such as Semnan, Qom, Yazd, and Markazi had the highest CCDs and means that such provinces are affected more than others by the novel coronavirus considering their population sizes. Based on the results, it seems that restricting movement and following health instructions should be considered more in these provinces. In addition, provinces located mostly in the center and northern center of Iran with significant population densities had relatively high CCDs. Among these provinces, Tehran, with the largest population, is reckoned to have a potential for COVID-19 infection that may lead to a critical situation unless strict health regulations are put in place. Given that pollutant levels have a prominent role in the virus outbreak, emissions reductions might be a useful approach to control the infection in these provinces. Therefore, some decisions such as setting low-emission zones to reduce daily commutes, prohibiting heavy-duty vehicles entry to high-risk regions, and limiting the work hours of power plants and refineries should be taken. The results reveal that air pollutant levels were influential in the period of the disease outbreak. The mean concentration of $\mathrm{CO}$ was high in 13 out of 31 provinces implying that there are more cases in areas with higher concentrations of $\mathrm{CO}$, and a similar trend for $\mathrm{NO}_{2}$ can be observed. Unlike $\mathrm{CO}$ and $\mathrm{NO}_{2}, \mathrm{O}_{3}$ had a somewhat different trend. Given the results, southern provinces that had lower CCDs were exposed to higher concentrations of $\mathrm{O}_{3}$ during the study period, even though it should be mentioned that the COVID-19 outbreak was assessed in the winter when surface ozone was more likely to have been destroyed by nitrogen oxides. Similar to $\mathrm{CO}$ and $\mathrm{NO}_{2}$, mean $\mathrm{SO}_{2}$ concentrations were significant in provinces. This shows that high-risk provinces were subjected to more $\mathrm{SO}_{2}$ pollution. It can be concluded 

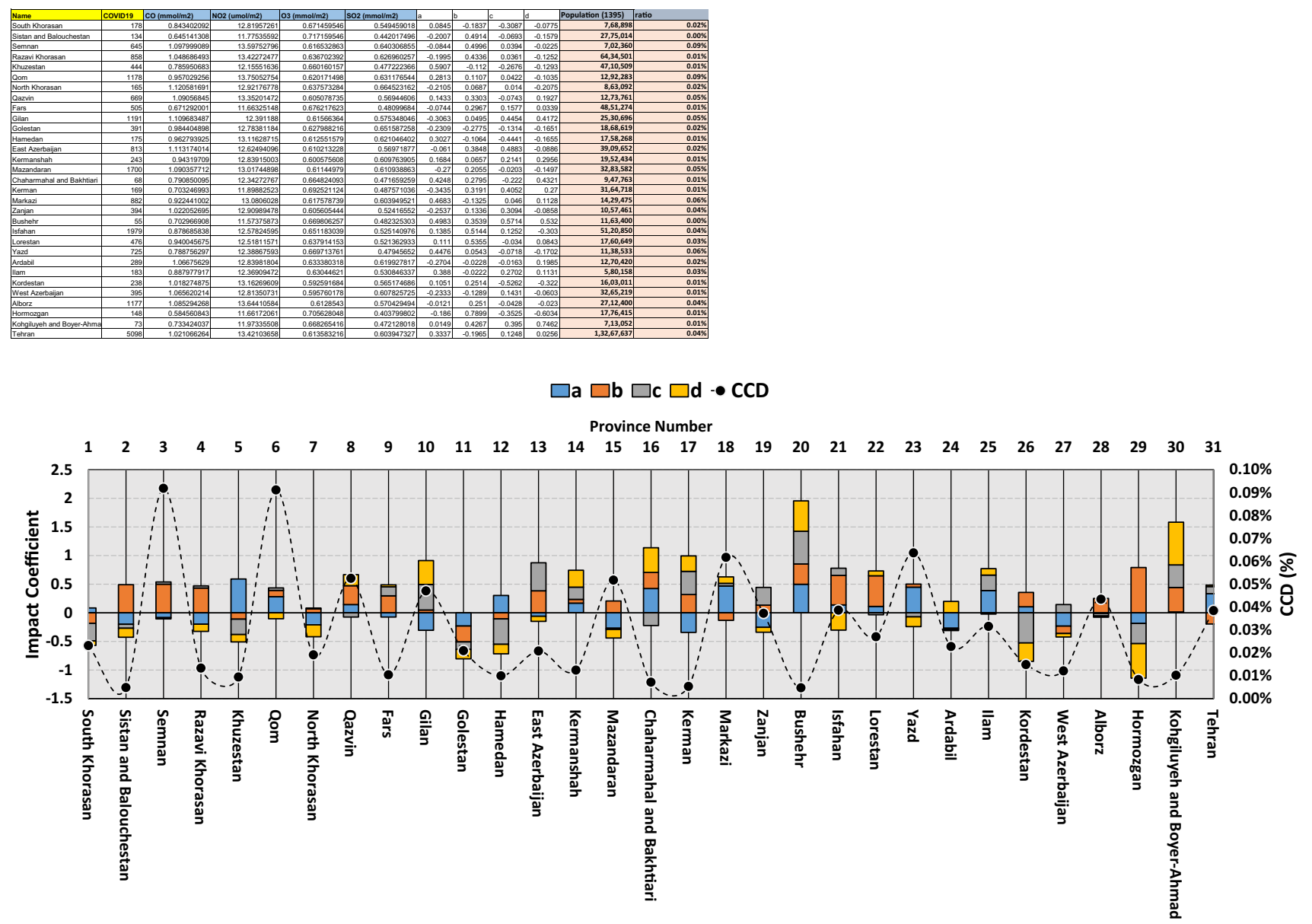

Fig. 5 Provincial impact coefficients

that provinces with larger CCDs, such as Semnan and Qom, had higher mean concentrations of almost all the pollutants.

In this study, significant negative and positive linear correlations have been found between the impact coefficients $a, b$, $d$, and $c$ and confirmed COVID-19 cases. However, the impact coefficient $d$ was correlated more negatively than positively with the density of confirmed cases among the provinces. These findings provide evidence that the air pollutants $\mathrm{CO}$, $\mathrm{NO}_{2}$, and $\mathrm{O}_{3}$ unlike $\mathrm{SO}_{2}$, mostly had relatively increasing rather than decreasing effects, even though all of them could be important contributing factors in COVID-19 infections.

Although almost all the air pollutants could be risk factors for the respiratory system, results demonstrated that impact coefficient $d$ had more decreasing effects on COVID-19 cases. Thus, to figure out the effect of $\mathrm{SO}_{2}$ precisely and comprehensively, additional research should be done. Based on the study results, in order to control COVID-19 infections, reducing emissions of $\mathrm{CO}, \mathrm{NO}_{2}$, and $\mathrm{O}_{3}$ could be effective, especially in provinces that have experienced larger COVID-19 outbreaks. Meanwhile, further research is needed to understand the effect of $\mathrm{SO}_{2}$ on infections and to illuminate its correlation with confirmed COVID-19 cases.

The current study has several constraints. First of all, only the association between air pollutants and the density of COVID-19 cases was considered, and the results did not address the effects of air pollutants on the disease transmission rate. Second, no distinction was considered for the gender or ages of confirmed cases, nor was the presence of background diseases taken into account. Also, various features of pollutant emission sources were not considered in the data used. Furthermore, the results of this study are mainly focused on Iran, and subsequent studies are required to generalize the conclusions.

\section{Conclusion}

The COVID-19 pandemic has affected many countries throughout the world, including both developed and developing countries, since late December 2019. Iran has varied provincial population densities and many highly air-polluted 
megacities that have different infection rates. Therefore, understanding the effects of major air pollutants on the spread of the virus is vital. Tehran, Isfahan, and Mazandaran provinces had the most COVID-19 confirmed cases, while Bushehr, Chaharmahal and Bakhtiari, and Kohgiluyeh and Boyer-Ahmad provinces had the least confirmed cases.

The COVID-19 CCDs showed that Semnan and Qom were affected by the virus more than other provinces. Nine central provinces had high CCDs, and collectively had $64 \%$ of all confirmed cases, while several southern provinces such as Bushehr and Sistan and Balouchestan had the lowest CCDs.

The Sentinel-5P data showed that the largest values of the mean concentrations of $\mathrm{CO}, \mathrm{NO}_{2}, \mathrm{O}_{3}$, and $\mathrm{SO}_{2}$ were measured in provinces, which had $63 \%, 58 \%, 20 \%$, and $55 \%$ of all COVID-19 cases. This shows that short-term exposure to larger concentrations of these pollutants could be an important factor leading to an increase in the risk of COVID-19 infection.

Based on the results of modeling, there is a considerable statistical relationship between air pollutants and COVID19 infection. The provinces with the largest values for the impact coefficients $a, b, c$, and $d$ held over $31 \%, 13 \%, 3 \%$, and 3\% of all confirmed COVID-19 cases, while the provinces with the lowest coefficients for $a, b, c$, and $d$ comprised over $22 \%, 37 \%, 33 \%$, and $9 \%$ of total confirmed cases. The provincial sensitivity analysis demonstrated that the influences of each impact coefficient on the density of confirmed COVID-19 cases were different. Among all provinces, the impact coefficients $a, b, c$, and $d$ had positive correlations, i.e., an increasing effect, in $16,22,17$, and 13 provinces, respectively. The value of impact coefficient $a$ was larger than that of the other coefficients in Qom, Yazd, and Markazi, which had high CCD values. This means that CO had the most significant effect on the density of confirmed cases. In Semnan, as a top hot spot province, the effect of $\mathrm{NO}_{2}$ was greater than that of $\mathrm{CO}$.

Since there is not yet any scientific reason which explains why $\mathrm{SO}_{2}$ had a decreasing effect on the density of confirmed virus cases, conducting more studies to shed light on the underlying mechanisms seems to be necessary.

Acknowledgments Authors would also like to acknowledge Iran's Ministry of Health and Medical Education for providing and sharing COVID-19 data.

\section{Compliance with ethical standards}

Conflict of interest The authors declare no conflict of interest.

Ethical approval This article does not contain any studies with human participants or animals performed by any of the authors.

\section{References}

Ahmadi M, Sharifi A, Dorosti S, Ghoushchi SJ, Ghanbari N (2020) Investigation of effective climatology parameters on COVID-19 outbreak in Iran. Sci Total Environ 729:138705

Bashir MF, Bilal BM, Komal B (2020) Correlation between environmental pollution indicators and COVID-19 pandemic: a brief study in Californian context. Environ Res 187:109652

Becker S, Soukup JM (1999) Exposure to urban air particulates alters the macrophage-mediated inflammatory response to respiratory viral infection. J Toxicol Environ Health Part A 57:445-457

Beelen R, Hoek G, van Den Brandt PA, Goldbohm RA, Fischer P, Schouten LJ, Jerrett M, Hughes E, Armstrong B, Brunekreef B (2008) Long-term effects of traffic-related air pollution on mortality in a Dutch cohort (NLCS-AIR study). Environ Health Perspect 116:196-202

Bell ML, McDermott A, Zeger SL, Samet JM, Dominici F (2004) Ozone and short-term mortality in 95 US urban communities, 1987-2000. J Am Med Assoc 292:2372-2378

Bontempi E (2020) First data analysis about possible COVID-19 virus airborne diffusion due to air particulate matter (PM): the case of Lombardy (Italy). Environ Res 109639

Cai QC, Lu J, Xu QF, Guo Q, Xu DZ, Sun QW, Yang H, Zhao GM, Jiang QW (2007) Influence of meteorological factors and air pollution on the outbreak of severe acute respiratory syndrome. Public Health 121:258-265

Chan JFW, Yuan S, Kok KH, To KKW, Chu H, Yang J, Xing F, Liu J, Yip CCY, Poon RWS (2020) A familial cluster of pneumonia associated with the 2019 novel coronavirus indicating personto-person transmission: a study of a family cluster. The Lancet 395:514-523

Chauhan AJ, Johnston SL (2003) Air pollution and infection in respiratory illness. Br Med Bull 68:95-112

Chen TM, Kuschner WG, Gokhale J, Shofer S (2007) Outdoor air pollution: nitrogen dioxide, sulfur dioxide, and carbon monoxide health effects. Am J Med Sci 333:249-256

Chen N, Zhou M, Dong X, Qu J, Gong F, Han Y, Qiu Y, Wang J, Liu Y, Wei Y (2020) Epidemiological and clinical characteristics of 99 cases of 2019 novel coronavirus pneumonia in Wuhan, China: a descriptive study. The Lancet 395:507-513

Ciencewicki J, Jaspers I (2007) Air pollution and respiratory viral infection. Inhal Toxicol 19:1135-1146

Copernicus. https://www.copernicus.eu/en. Accessed 10 June 2019

Domingo JL, Rovira J (2020) Effects of air pollutants on the transmission and severity of respiratory viral infections. Environ Res 187:109650

Filippidou EC, Koukouliata A (2011) Ozone effects on the respiratory system. Prog Health Sci 1:144-155

Gryparis A, Forsberg B, Katsouyanni K, Analitis A, Touloumi G, Schwartz J, Samoli E, Medina S, Anderson HR, Niciu EM (2004) Acute effects of ozone on mortality from the "air pollution and health: a European approach" project. Am J Respir Crit Care Med 170:1080-1087

Guo YR, Cao QD, Hong ZS, Tan YY, Chen SD, Jin HJ, Tan KS, Wang DY, Yan Y (2020) The origin, transmission and clinical therapies on coronavirus disease 2019 (COVID-19) outbreakan update on the status. Mili Med Res 7:1-10

Hoek G, Krishnan RM, Beelen R, Peters A, Ostro B, Brunekreef B, Kaufman JD (2013) Long-term air pollution exposure and cardio-respiratory mortality: a review. Environ Health 12:43

Horne BD, Joy EA, Hofmann MG, Gesteland PH, Cannon JB, Lefler JS, Blagev DP, Korgenski EK, Torosyan N, Hansen GI (2018) Short-term elevation of fine particulate matter air pollution and acute lower respiratory infection. Am J Respir Crit Care Med 198:759-766 
Huang C, Wang Y, Li X, Ren L, Zhao J, Hu Y, Zhang L, Fan G, Xu J, Gu X (2020) Clinical features of patients infected with 2019 novel coronavirus in Wuhan, China. The Lancet 395:497-506

İçağa Y, Sabah E (2009) Statistical analysis of air pollutants and meteorological parameters in Afyon, Turkey. Environ Model Assess 14:259-266

Jahangiri M, Jahangiri M, Najafgholipour M (2020) The sensitivity and specificity analyses of ambient temperature and population size on the transmission rate of the novel coronavirus (COVID19) in different provinces of Iran. Sci Total Environ 728:138872

Jiang F, Deng L, Zhang L, Cai Y, Cheung CW, Xia Z (2020) Review of the clinical characteristics of coronavirus disease 2019 (COVID19). J General Intern Med 35:1-5

Khoder M (2002) Atmospheric conversion of sulfur dioxide to particulate sulfate and nitrogen dioxide to particulate nitrate and gaseous nitric acid in an urban area. Chemosphere 49:675-684

Kraemer MU, Yang CH, Gutierrez B, Wu CH, Klein B, Pigott DM, du Plessis L, Faria NR, Li R, Hanage WP (2020) The effect of human mobility and control measures on the COVID-19 epidemic in China. Science 368:493-497

Li Q, Guan X, Wu P, Wang X, Zhou L, Tong Y, Ren R, Leung KS, Lau EH, Wong JY (2020) Early transmission dynamics in Wuhan, China, of novel coronavirus-infected pneumonia. New Engl J Med 382:1199-1207

Lu R, Zhao X, Li J, Niu P, Yang B, Wu H, Wang W, Song H, Huang $\mathrm{B}$, Zhu N (2020) Genomic characterisation and epidemiology of 2019 novel coronavirus: implications for virus origins and receptor binding. The Lancet 395:565-574

Mehta S, Shin H, Burnett R, North T, Cohen AJ (2013) Ambient particulate air pollution and acute lower respiratory infections: a systematic review and implications for estimating the global burden of disease. Air Qual Atmos Health 6:69-83

Mehta P, McAuley DF, Brown M, Sanchez E, Tattersall RS, Manson JJ (2020) COVID-19: consider cytokine storm syndromes and immunosuppression. The Lancet 395:1033-1034

Ng KY, Awang N (2018) Multiple linear regression and regression with time series error models in forecasting $\mathrm{PM}_{10}$ concentrations in Peninsular Malaysia. Environ Monit Assess 190:63

Ogen Y (2020) Assessing nitrogen dioxide $\left(\mathrm{NO}_{2}\right)$ levels as a contributing factor to the coronavirus (COVID-19) fatality rate. Sci Total Environ 726:138605

Omrani H, Omrani B, Parmentier B, Helbich M (2020) Spatio-temporal data on the air pollutant nitrogen dioxide derived from Sentinel satellite for France. Data Brief 28:105089

Parodi S, Vercelli M, Garrone E, Fontana V, Izzotti A (2005) Ozone air pollution and daily mortality in Genoa, Italy between 1993 and 1996. Public Health 119:844-850

Phan LT, Nguyen TV, Luong QC, Nguyen TV, Nguyen HT, Le HQ, Nguyen TT, Cao TM, Pham QD (2020) Importation and humanto-human transmission of a novel coronavirus in Vietnam. New Engl J Med 382:872-874

Phosri A, Ueda K, Phung VLH, Tawatsupa B, Honda A, Takano H (2019) Effects of ambient air pollution on daily hospital admissions for respiratory and cardiovascular diseases in Bangkok, Thailand. Sci Total Environ 651:1144-1153

Putrenko VV, Pashynska NM (2017) The use of remote sensing data for modeling air quality in the cities. ISPRS Ann PhotogramRemote Sens Spat Inf Sci 4:57
Rastogi YR, Sharma A, Nagraik R, Aygün A, Şen F (2020) The novel coronavirus 2019-nCoV: its evolution and transmission into humans causing global COVID-19 pandemic. Int J Environ Sci Technol 17:1

Rodriguez-Morales AJ, Bonilla-Aldana DK, Tiwari R, Sah R, Rabaan AA, Dhama K (2020) COVID-19, an emerging coronavirus infection: current scenario and recent developments-an overview. J Pure Appl Microbiol 14:6150

Smith TJ, Peters JM, Reading JC, Castle CH (1977) Pulmonary impairment from chronic exposure to sulfur dioxide in a smelter. Am Rev Respir Dis 116:31-39

Sohrabi C, Alsafi Z, O’Neill N, Khan M, Kerwan A, Al-Jabir A, Iosifidis C, Agha R (2020) World Health Organization declares global emergency: a review of the 2019 novel coronavirus (COVID-19). Int J Surg 76:71-76

Sousa S, Martins FG, Alvim-Ferraz M, Pereira MC (2007) Multiple linear regression and artificial neural networks based on principal components to predict ozone concentrations. Environ Model Softw 22:97-103

Ul-Saufie AZ, Yahaya AS, Ramli N, Hamid HA (2012) Performance of multiple linear regression model for long-term PM10 concentration prediction based on gaseous and meteorological parameters. J Appl Sci 12:1488-1494

Van Doremalen N, Bushmaker T, Morris DH, Holbrook MG, Gamble A, Williamson BN, Tamin A, Harcourt JL, Thornburg NJ, Gerber SI (2020) Aerosol and surface stability of SARS-CoV-2 as compared with SARS-CoV-1. New Engl J Med 382:1564-1567

Wan J, Tang K, Feng K, Lv W (2020b) High temperature and high humidity reduce the transmission of COVID-19. Available at SSRN 3551767

Wang D, Hu B, Hu C, Zhu F, Liu X, Zhang J, Wang B, Xiang H, Cheng Z, Xiong Y (2020) Clinical characteristics of 138 hospitalized patients with 2019 novel coronavirus-infected pneumonia in Wuhan, China. J Am Med Assoc 323:1061-1069

WHO (2020a) World Health Organization Coronavirus disease 2019 (COVID-19) Situation Report-31

WHO (2020b) World Health Organization Coronavirus disease 2019 (COVID-19) Situation Report-51

WHO (2020c) World Health Organization Coronavirus disease 2019 (COVID-19) Situation Report-63

Xie J, Teng J, Fan Y, Xie R, Shen A (2019) The short-term effects of air pollutants on hospitalizations for respiratory disease in Hefei, China. Int J Biometeorol 63:315-326

Xu Q, Li X, Wang S, Wang C, Huang F, Gao Q, Wu L, Tao L, Guo J, Wang W (2016) Fine particulate air pollution and hospital emergency room visits for respiratory disease in urban areas in Beijing, China, in 2013. PLoS ONE 11(4):e0153099

Xu Z, Shi L, Wang Y, Zhang J, Huang L, Zhang C, Liu S, Zhao P, Liu H, Zhu L (2020) Pathological findings of COVID-19 associated with acute respiratory distress syndrome. Lancet Respir Med $8: 420-422$

Yongjian Z, Jingu X, Fengming H, Liqing C (2020) Association between short-term exposure to air pollution and COVID-19 infection: Evidence from China. Sci Total Environ 727:138704

Zhu Y, Xie J (2020) Association between ambient temperature and COVID-19 infection in 122 cities from China. Sci Total Environ 724:138201 